\title{
Critical Look at Operative Dentistry
}

Traditional operative treatment of dental caries has many short comings, ranging from idiosyncratic treatment planning to the use of out-dated cavity designs. These and other factors rather easily contribute to a repeat restoration cycle with restorations themselves not lasting many years. There is a clear need to move towards a truely preventive form of caries management, with the dentist placing modern restorations in high quality conservative cavity preparations on a selective basis.
"A fundamental issue facing dentistry and oral health care is the relevance of current practices to the needs of the future".(1) This was included in the Summary Statement resulting from the 1988 Bristol International Dental Conference entitled "Decisions in forward-looking oral health care" - and it correctly implies that dental practice in the future will differ from that of the present. Also contained in the Summary Statement was "It is easy to believe that dental treatment automatically results in oral health". It is, therefore, not surprising that the traditional restorative approach treatment per se has been shown to have many shortcomings and does not, on its own, ensure oral health. In spite of this, the majority of the world's dentists work in towns and cities where current practice usually includes a sizeable component of dental treatment in the form of operative dentistry. Certainly most dentists have been trained in dental schools that are somewhat dominated by large restorative departments; operative techniques have to be taught, but the mere fact that they are taught means that they rather readily come to form the basis of teaching and of subsequent practice.

How satisfatory are dental restorations as a method of caries management? The first thing to appreciate is that operative treatment can be very effective in restoring function and aesthetics - and with operative treatment, many teeth that would otherwise be lost are kept functioning. But dental caries is a disease of lifestyle, and
R J Elderton

Professor of Preventive and Restorative Dentistry

University of Bristol

Dental School

Lower Maudlin Street

Bristol BS1 2LY

UK dental restorations do not change lifestyles. Indeed, they suffer from a number of problems and intrinsic failure characteristics which need to be fully understood if operative dentistry is to be placed within a context appropriate for the decades ahead and if the profession is to avoid questions being raised about possible unnecessary treatment(2).

\section{PROBLEMS WITH TREATMENT PLANNING}

\section{Inaccurate diagnosis of caries}

Athough dentists have been trained to diagnose caries, it should not be assumed that they are infallible in this respect, nor that all dentists use the same clinical criteria when so doing. Thus, when groups of dentists have been asked to examine the same patients, enormous differences have been found in terms of precisely which teeth, and how many, they consider have carious lesions(3). Some caries diagnoses made on a day-to-day basis around the world must be incorrect.

The assessment of secondary caries may present greater diagnostic problems than with primary caries. Thus, when a group of nine dentistis examined 228 extracted restored teeth in a simulated clinical study, there was nearly a six-fold difference between the dentitst in the number of teeth which they stated had secondary caries.(4) Further, 
there was a considerable lack of correspondence between the teeth identified clinically as having caries, and those which were found, after sectioning, to have caries. And in many instances, the dentists admitted that they did not know whether or not secondary caries was present. As a large amount of restorative treatment concerns replacing existing restorations(5), the potential consquences of such unsatisfactory or inaccurate diagnoses are far-reaching.

\section{Idiosyncratic restorative treatment decisions}

The above problems with diagnosis are, not surprisingly, reflected in the idiosyncratic nature of many restorative decisions, and considerable variation in this respect has been noted in a number of studies. Thus, in an investigation in which 15 dentists each examined and planned treatment for a group of 18 young adults, the total number of decisions to restore ranged across the dentists from 20 to 153(6). This demonstrates that considerable confusion exists among dental practitioners as to precisely which criteria they feel should be used when deciding upon the need to place or replace a restoration.

\section{PROBLEMS WITH REPLACING RESTORATIONS}

\section{Inability to identify the causes of failure of restorations}

Having perceived a restoration as being in need of replacement (ie failed), dentists are often unable to state the cause of failure. Thus the nine dentists in the extracted teeth study above(4), gave widely differing reasons for the breakdown that had occurred at the edges of the restorations they examined. The dentists cannot all have been right; indeed, an objective study has confirmed that the majority of reasons give for marginal failure of restorations are incorrect(7). So it is hardly surprising that errors are repeated and therefore that replacement restorations frequently contain the same unfavourable characteristics as their predecessors(7).

Thus, as with new restorations, replacement restorations are ofen doomed to failure from the start; and, sadly, clinicians are generally unaware of the faults in their new restorations. Indeed, in a study involving 170 newly replaced occlusal amalgam restorations, which were mostly shown by objective means to be very poor, the dentists who undertook them nevertheless assessed all of them as satisfactory(7). This is in spite of the fact that in $23 \%$ of instances, these same clinicians reported "don't know" as the reason for the marginal failure in the restorations they had just replaced.

\section{Restorations get larger}

As restorations are replaced, so cavities increase in size(7) and teeth become weaker. This is exacerbated by an apparent desire by some dentists to "freshen up the margins" of their cavities before inserting their new restorations. Fractured cups are becoming increasingly common as less and less sound dentine remains.

It is inevitable that as the amount of tooth substance left to hold a restoration in place diminishes, so the restoration becomes more complex. Sometimes this must mean that it will be more demanding on the dentist and therefore potentially subject to even greater operator defects. Costs inevitably rise, especially when crowns or other laboratory-made restorations are used to restore teeth that have had a series of repeat "simpler" restorations.

\section{PROBLEMS RELATING TO DENTISTS’ ATTITUDES}

Dentists who adopt an aggressively treatment-orientated approach to caries management and/or restoration maintenance may, in addition to doing too many new or replacement restorations, unqittingly fail to allow existing ones to achieve their full potential. Thus, in a five-year longitudinal study of dental treatment received by a randomly selected group of dentate adults, it was found that $50 \%$ of the restorative treatment was directed at just $12 \%$ of the people(5). These individuals (who tended to be the regular attenders) were a high risk group - at high risk of having their restorations replaced. It is clear that some dentists have a special impulse to want to replace restorations that they did not themselves place; thus, while patients in the above study who went to the same dentist approximately annually over the five years received an average of 7.4 restorations, a similar group of patients who changed their dentists once or more during the period received an average of 13.6 restorations(8), almost twice as many.

It seems that a heavily restored dentition may reflect the philosophy of the dentists who have provided treatment, at least as much as the level of caries experienced by the patient. And by placing restorations, dentists appear sometimes to exonerate themselves from any responsibility for helping their patients to control the disease processes. But modern understanding confirms that without such control, restorative treatment for caries is generally in effective and that it should only be undertaken in a preventive setting with attempts being made to help the patient control the disease processes(9). 


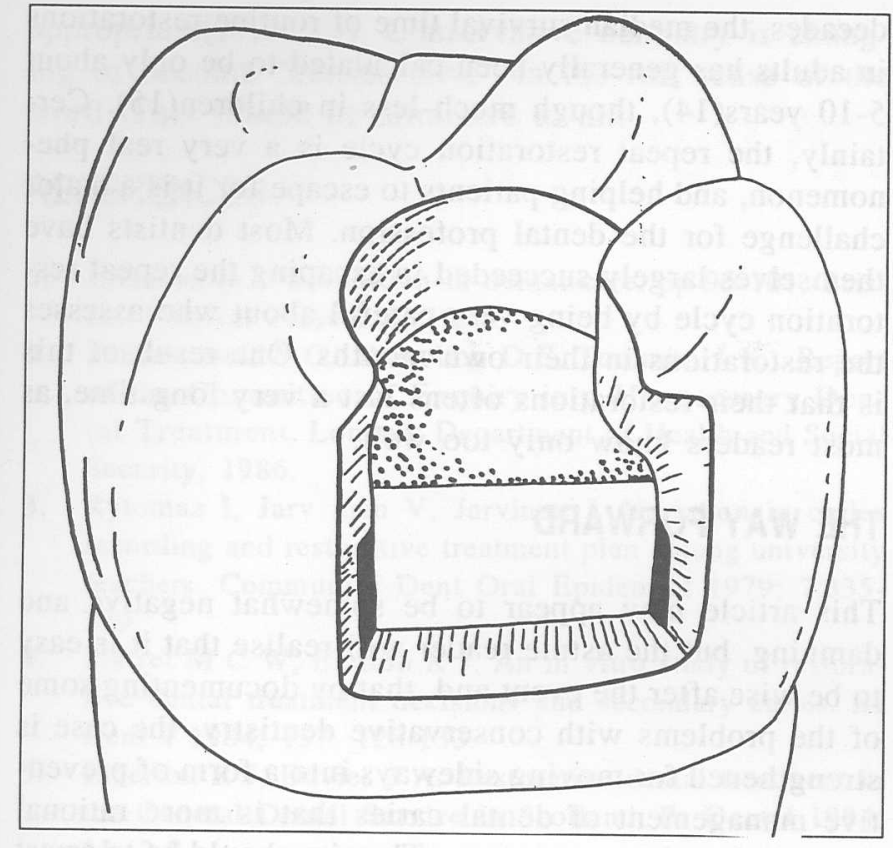

Fig. 1 Diagram showing an out-dated cavity preparation for amalgam or composite resin

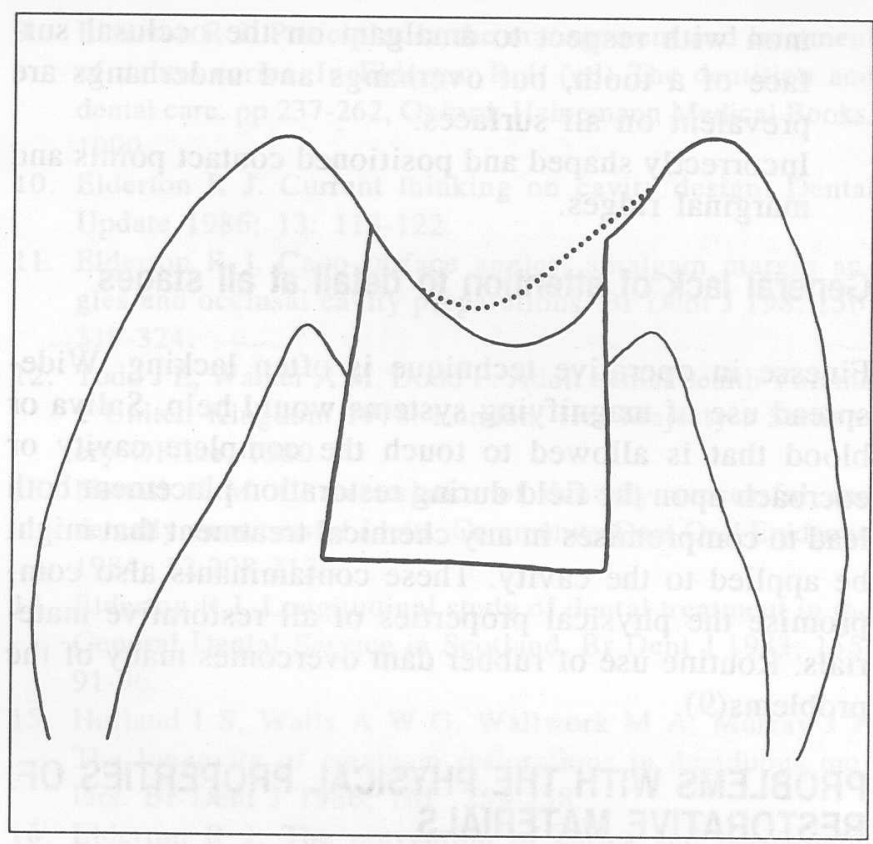

Fig. 2 Diagram showing a bucco-lingual section through an out-dated occlusal amalgam restoration. On the left the amalgam has been carved to a thin edge because the cavity wall has been prepared incorrectly (compare with Fig. 3). Two common additional faults are shown on the right: the restorative material left in excess in a region out of direct occlusal contact (dotted line); and the restorative material over-carved (solid line).

essential for allowing a bulk of restorative material and for the prevention of subsequent failure through recurrent caries or material breakdown. It does not require much imagination to realize that maintaining a bulk of sound remaining tooth substance is a more laudable objective.

\section{Incorrectly placed restorations}

Some common faults in restorations relate directly to the above and include:

- Weak amalgam margins of occlusal restorations.(11) These occur when the walls of the cavity have been prepared approximately in line with the long axis of the tooth and have high cavo-surface angles. The amalgam is then, somewhat inevitably, carved to a 'thin' edge in order to accommodate the opposing occlusion (Fig. 2). Such thin eges of amalgam are unlikely to survive long in clinical function without break down.

- Poorly adapted restorative material (Fig. 2), ie the restorative material in left short of the cavity margin or in excess(11). These are both particularly com- 
mon with respect to amalgam on the occlusal surface of a tooth, but overhangs and underhangs are prevalent on all surfaces.

Incorrectly shaped and positioned contact points and marginal ridges.

\section{General lack of attention to detail at all stages}

Finesse in operative technique is often lacking. Widespread use of magnifying systems would help. Saliva or blood that is allowed to touch the complete cavity or encroach upon the field during restoration placement both lead to compromises in any chemical treatment that might be applied to the cavity. These contaminants also compromise the physical properties of all restorative materials. Routine use of rubber dam overcomes many of the problems(9).

\section{PROBLEMS WITH THE PHYSICAL PROPERTIES OF RESTORATIVE MATERIALS}

No restorative material has ideal physical properties. Characteristics that are particularly liable to lead to shortcomings in restorations include not only those relating to rather obvious things like strength (bulk and marginal), wear, corrosion resistance and appearance; but also to factors like polymerization shrinkage, dimensional and chemical stability, and moisture absorption, which may rather insidiously have significant effects upon the integrity of the restoration, especially its marginal seal. Biocompatibility and thermal diffusivity may also be critical.

\section{PROBLEMS RELATING DIRECTLY TO PATIENTS}

Many patients appear rather to presume that restorations look after themselves, indeed that they are the dentist's responsibility. Compliance with home care instructions is therefore often unsatisfactory. Further, most patients who accept restorative dentistry see it as a neccessary evil. Other people simply avoid going to a dentist if at all possible, for they do not like what they think they might get if they do go(12). Certainly, recent data indicate that a restoratively orientated dental service offers something that many people do not want and that it does not fulfil their needs - however, the portents are that some of these people might come to accept care in a service with a predominantly preventive image(13).

\section{SHORT DURABILITY OF RESTORATIONS}

All the above factors appear to work together, with the result that many restorations survive in the mouth for only a short time. While restorations can last for many decades, the median survival time of routine restorations in adults has generally been calculated to be only about 5-10 years(14), though much less in children(15). Certainly, the repeat restoration cycle is a very real phenomenon, and helping patients to escape for it is a major challenge for the dental profession. Most dentists have themselves largely succeeded in escaping the repeat restoration cycle by being very careful about who assesses the restorations in their own mouths. One result of this is that their restorations oftens last a very long time, as most readers know only too well.

\section{THE WAY FORWARD}

This article may appear to be somewhat negative and damning, but the astute reader will realise that it is easy to be wise after the event and, that by documenting some of the problems with conservative dentistry, the case is strengthened for moving sideways into a form of preventive management of dental caries that is more rational and which makes more sense. The aim should be to arrest established lesions, indeed prevent such lesions from starting in the first place. The methodology for this is well established(16). The neccessary conceptual change has very definitely been launched and the future is therefore optimistic. Patients should be motivated to accept responsibility to change the environment of their teeth so that the calcium and phosphate balance favours remineralization, though with the dentist placing therapeutic fissure sealants or modern, high quality, restorations (Fig. 3) as

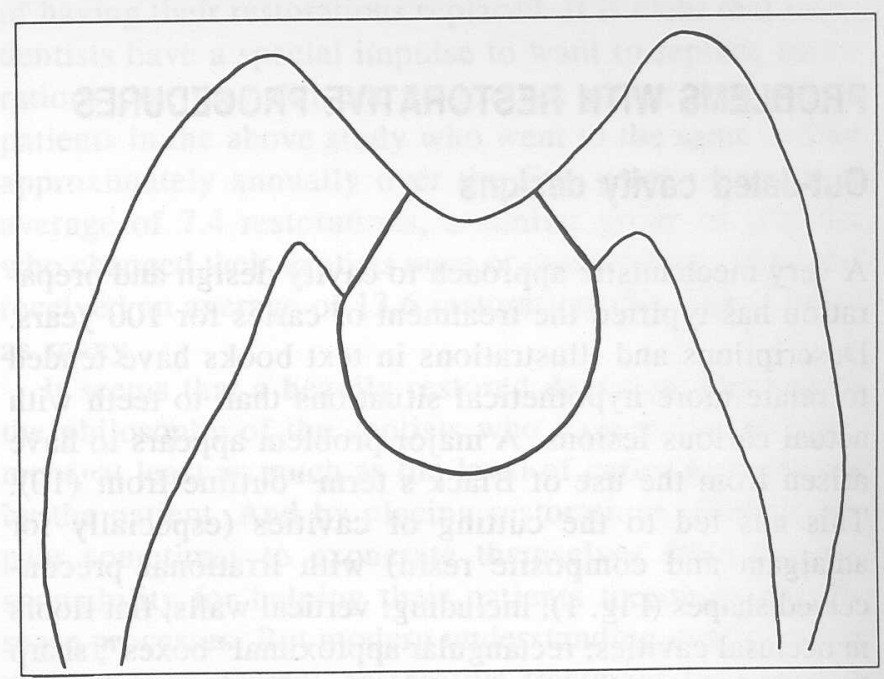

Fig. 3 Diagram similar to that in Fig. 2, but with a modern cavity design for amalgam or composite resin. The geometry is correct, allowing for strong restoration margins. Both this cavity and the one shown in Fig. 2 are the same width at the enamel-dentine junction, and the same depth, and thus relate to similar-sized carious lesions. 
appropriate $(17,18,19)$. Conservative dentistry is changing to become "conservative" in the full sense of the word. This should be attractive to all.

\section{REFERENCES}

1. Elderton R J. E volution in dental care. pp 95-101, Bristol: Clinical Press Ltd, 1990.

2. Schanschieff S G, Shovelton D S, Toulmin, J K . Report of the Committee of Enquiry into Unnecessary Dental Treatment. London: Department of Health and Social Security, 1986.

3. Rytomaa I, Jarv inen V, Jarvinen J. Variation in caries recording and restorative treatment plan among university teachers. Community Dent Oral Epidemiol 1979; 7:335339.

4. Merret M C W, Elerton R J. An in vitro study of restorative dental treatment decisions and secondary caries. $\mathrm{Br}$ Dent J 1984; 157: 128-133.

5. Elderton R J, Davies J A. Restorative dental treatment in the General Dental Service in Scotland. Br Dent J 1984; 11: 2-8.

6. Elderton R J, Nuttall N M. Variation among dentists in planning treatment. Br Dent J 1983; 154: 201-206.

7. Elderton R J. The quality of amalgam restorations. In Alired $\mathrm{H}$ (ed) Assessment of the quality of dental care. pp 45-81, London: London Hospital Medical College, 1977.

8. Davies $\mathbf{J}$ A. The relationship between change of dentist and treatment received in the General Dental Service. Br. Dent J 1984; 157: 322-324.
9. Elderton R J. Principles in the management and treatment of dental caries. In Elderton R J. (ed) The dentition and dental care. pp 237-262, Oxford: Heinemann Medical Books, 1990.

10. Elderton R J. Current thinking on cavity design. Dental Update 1986; 13: 113-122.

11. Elderton R J. Cavo-surface angles, amalgam margin angles and occlusal cavity preparations. Br Dent J 198; 156: 319-324.

12. Todd J E, Walker A M, Dodd P. Adult dental health Volume 2 United Kingdom 1978. London: Her Majesty's Stationery OFfice, 1980.

13. Nuttall N M. Characteristics of dentally successful and dentally unsuccessful adults. Community Dent Oral Epidemio $1984 ; 12: 208-212$

14. Elderton R J. Longitudinal study of dental treatment in the General Dental Service in Scotland. Br Dent J 1983; 155: 91-96.

15. Holland I S, Walls A W G, Wallwork M A, Murray J J. The longevity of amalgam restorations in deciduous molars. Br Dent J 1986; 161: 255-258.

16. Elderton R J. The prevention of caries and periodontal diseases. In Elderton R J (ed) The dentition and dental care. pp 139-163, Oxford: Heinemann Medical Books, 1990.

17. Elderton R J. Assessment and clinical management of early caries in young adults: non-invasive versus invasive techniques. Br Dent I 1985; 158: 440-444.

18. Elderton R J . Management of early dental caries in fissures with fissure sealant. Br Dent J 1985; 158: 254-258.

19. Elderton R J Restorations without conventional cavity preparations. Int Dent J 1988; 38: 112-118. 